\title{
The economics of mental health
}

\section{With modern psychological therapy, mentally ill people can become more productive and more satisfied with life}

Keywords: mental illness, psychological therapy, health, life-satisfaction

\section{ELEVATOR PITCH}

In a typical country, one in five people suffers from a mental illness, the great majority from depression or crippling anxiety. Mental illness accounts for half of all illness up to age 45 in rich countries, making it the most prevalent disease among working-age people; it also accounts for close to half of disability benefits in many countries. Mentally ill people are less likely to be employed and, if employed, more likely to be out sick or working below par. If mentally ill people received treatment so that they had the same employment rate as the rest of the population, total employment would be $4 \%$ higher, adding many billions to national output.

\section{KEY FINDINGS}

\section{Pros}

- Mental illness costs billions in welfare payments and lost taxes.

- Psychological therapy boosts both employment and output, with gains exceeding the cost of treatment.

( Psychological therapy is a bargain: for each $\$ 1$ spent, roughly $\$ 1$ is saved on welfare benefits and another $\$ 1$ is saved on physical health care.

๑ Psychological treatment can reduce a person's annual physical health care costs by $20 \%$.

๑ Curing all depression and anxiety disorders would boost GDP by some $4 \%$.
Mental illness is the main health problem for people of working age in richer countries, 2008

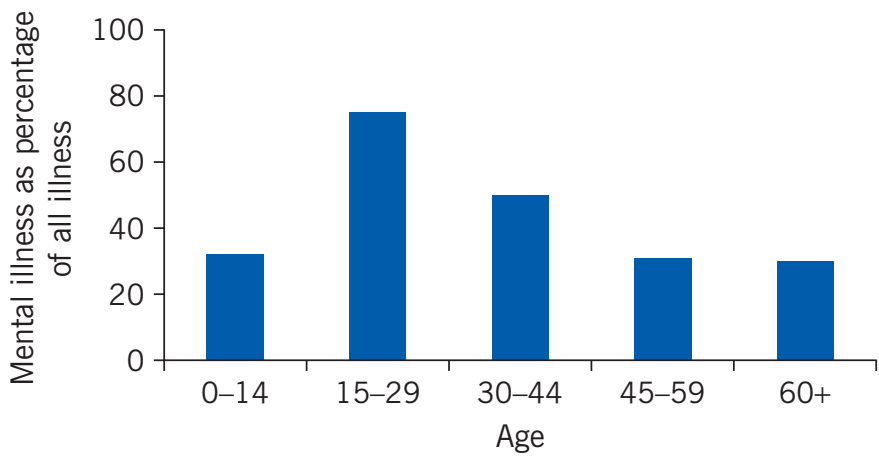

Source: Layard, R., and D. M. Clark. Thrive: The Power of Evidencebased Psychological Therapies. London: Penguin, 2014. I Z A World of Labor

\section{Cons}

- In most countries, only a tiny minority of people with depression or anxiety disorders receive evidence-based psychological therapy.

- Nearly one in five adults worldwide suffers from a diagnosable mental illness.

- Mental illness accounts for $38 \%$ of all illness in rich countries.

- People with mental health problems who are also physically ill typically use $60 \%$ more physical health care than equally ill people without mental health problems.

- The extra physical care of people with a mental illness costs close to $1 \%$ of national income.

\section{AUTHOR'S MAIN MESSAGE}

Providing evidence-based therapies for people with a mental illness should be at the heart of public policymaking, given the burden of mental illness and the payoff to extending treatment. As common in poor countries as in rich ones, mental illness reduces employment and productivity. By keeping so many people from working or from working productively, mental illness costs billions in welfare payments and lost taxes. By contrast, therapy boosts both employment and output, with gains exceeding the cost of treatment. It also produces savings in physical health care-as much as $20 \%$ of an individual's annual costs-and improves life-satisfaction. 


\section{MOTIVATION}

Mental health is a major factor in national economies both because mental illness is so common and because it is so disabling. The great majority of people with a mental illness suffer from clinical depression or crippling anxiety disorders. For a typical country, nearly one in five adults suffers from a diagnosable mental illness. The World Health Organization (WHO) repeatedly points out that mental illness is a worldwide problem [1]. Mental illness is as common in poorer countries as it is in richer ones. It causes not only massive suffering but also great economic waste, because it is particularly a disease of people of working age. In rich countries physical illness is mainly a disease of old age, and mental illness accounts for more than half of all illness up to the age of 45 (see the illustration on p. 1). The costs are huge. But effective evidence-based treatments are not expensive, and they generate massive savings. In fact, they can more than pay for themselves in savings in the labor market and in physical health care. Dealing with mental health problems is not only an economic imperative but a matter of common humanity.

\section{DISCUSSION OF PROS AND CONS}

\section{Burden of mental illness}

It is natural to ask how mental illness compares with physical illness. One could simply compare the number of people with each type of clinical condition. But this would fail to reflect the degree of pain caused by the different illnesses and how much they interfere with normal living. For example, one study compared the degree of disability caused by depression with that caused by four of the most common chronic physical illnessesdiabetes, angina, asthma, and arthritis-and found that depression is 50\% more severe and disabling than any of the other four illnesses [2].

The WHO developed a methodology for evaluating the scale of illness by taking the number of people suffering from each illness and weighting the number by the degree of disability that each one causes [1]. The results are astonishing. In rich countries, mental illness accounts for $38 \%$ of the total amount of illness (Figure 1). This contrasts with $6 \%$ for cardiovascular disease and even less for diabetes. Of mental illnesses, depression and anxiety disorders account for more than half the total.

Figure 1. Mental illness accounts for $38 \%$ of all ill health in richer countries, 2008

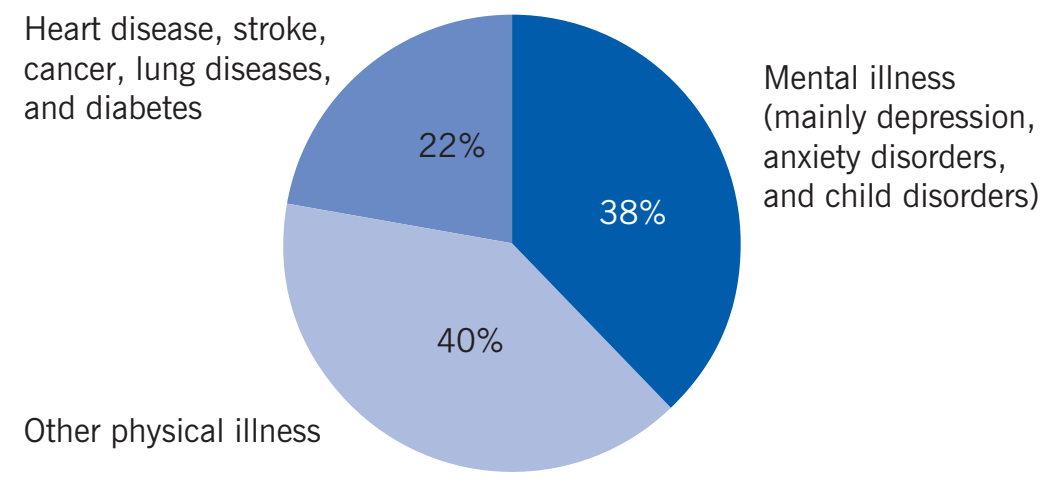

Source: Calculations based on data from WHO. The Global Burden of Disease: 2004 Update. Geneva: WHO, 2008 [1]. 


\section{The costs of non-employment, absenteeism, and presenteeism}

The economic impact of these conditions is huge. People who are mentally ill are less likely to be in work and, if in work, are more likely to be out sick or working below par.

More than a third of all disability comes directly from mental illness. This is true in the UK, the US, and continental Europe (Figure 2). Altogether, roughly $6 \%$ of working-age adults are receiving disability benefits, and more than a third of these benefits are for explicit reasons of mental illness [3]. On top of this, many people who report physical illness, like back pain or headache, have medically unexplained symptoms that are psychosomatic in origin. So, close to $50 \%$ of disability benefits are directly due to mental illness.

If mentally ill people worked as much as the rest of the population, total employment would be more than $4 \%$ higher [3]. That would mean billions more in output. Some of this loss is borne by the individuals themselves, but a substantial amount is borne by everyone as taxpayers.

Figure 2. Percentage of people of working age who are on disability benefits, 2011

\begin{tabular}{lll}
\hline Country & $\begin{array}{l}\text { On disability for } \\
\text { mental illness }\end{array}$ & $\begin{array}{l}\text { On disability for } \\
\text { any reason }\end{array}$ \\
\hline UK & 2.5 & 6.1 \\
US & 2.0 & 6.6 \\
Average of six other OECD & 2.4 & 6.4 \\
countries $^{\text {a }}$ & & \\
\hline
\end{tabular}

Note: a. The six countries are Australia, Belgium, the Netherlands, Norway, Sweden, and Switzerland.

Source: OECD. Sick on the Job? Myths and Realities about Mental Health and Work. Paris: OECD Publishing, 2012; Figure 4.2.

Moreover, mental health problems make it harder to perform well at work. Mentally ill people are much more likely to be out sick. Between a third and half of all days off work are attributable to mental illness. Sometimes the absence is due mainly to the atmosphere at work, but in at least $80 \%$ of cases it is due to an underlying mental health problem that makes it impossible to cope.

"Presenteeism" is another cost of mental illness-the less effective work done when a person is suffering from a mental illness. More difficult to measure than absenteeism, presenteeism has been studied mainly by asking people questions about how much below their best work effort they are putting in each day. A comparison of mentally ill people with others shows that presenteeism due to mental illness reduces output by at least as much as absenteeism does [4].

So mental health problems affect the output of the economy through non-employment, absenteeism, and presenteeism. By a conservative analysis, the combined effect in the UK, for example, is to reduce national income (gross national product) by $7 \%$-almost as much as most countries spend on education. Half of this cost falls on taxpayers (Figure 3). 
Figure 3. Mental illness imposes high costs on the economy and taxpayers in the UK, 2009/2010

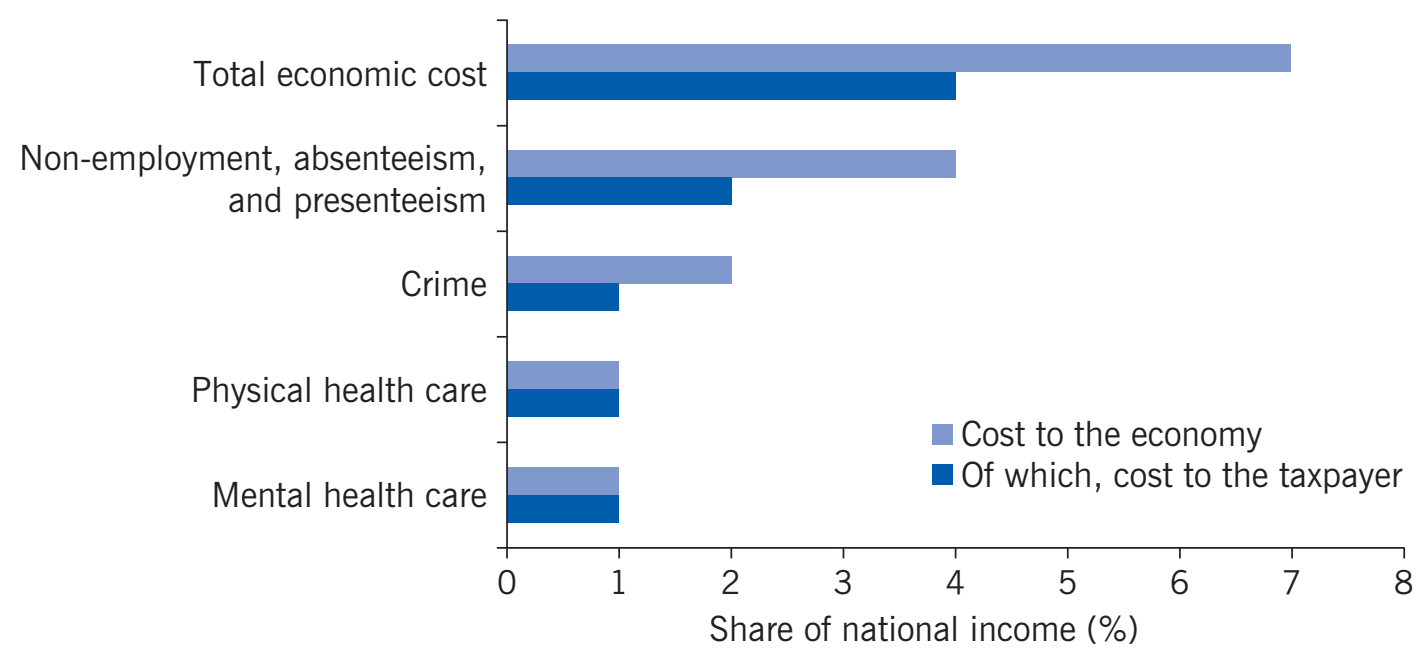

Source: Author's calculations based on data from Centre for Mental Health. The Economic and Social Costs of Mental Health Problems in 2009/10. London: Centre for Mental Health, 2010.

\section{Higher costs for physical health care}

Mental illness also imposes costs on physical health care. Mental health problems often make physical health problems worse-typically increasing mortality by $50 \%$ for people with the same initial health conditions. So, not surprisingly, mental health problems also add greatly to the cost of physical health care.

Mentally ill people cost significantly more than others in their physical health care. Consider some striking figures of depression from the Colorado Access insurance system in the US. The typical finding is that people who have mental health problems use $60 \%$ more physical health care services than equally ill people without mental health problems.

This massive extra cost (in England it amounts to $£ 10$ billion) comes through a variety of channels [5]. For one thing, people with mental health problems do not look after themselves as well-for example, getting less exercise and skipping regular medication. Their stressed mental state also has direct physiological effects. And mentally ill people are more inclined to worry and therefore to visit the doctor.

There is also the related problem of people who have medically unexplained symptomspeople who have no diagnosed physical condition but who do have serious pain. They are much more likely to go to a doctor and to have more medical tests than the rest of the population. Using a variety of international data, it is possible to calculate the cost of the extra health services used by this group compared with everyone else in the population. In the UK, the figure comes to $£ 3$ billion annually.

Not all people with medically unexplained physical symptoms are mentally ill, and some of their physical health care costs are already included in the previous estimate of cost. But even so, the extra physical care of those who are mentally ill costs close to $1 \%$ of national income in the UK. Similar figures are likely to apply in most advanced countries. The figure would be even higher in the US, where health care costs take up so much more of the national income. 


\section{The costs of crime}

Finally, much crime is mental health-related, and this crime has a clear economic cost. In richer countries, many crimes are committed by people with a prior diagnosis of conduct disorders. Indeed, a third of all crime is committed by people who already had a conduct disorder by the ages of seven to nine [6].

In the UK, the overall cost of all crime is estimated at $5 \%$ of national income [6]. This estimate includes property loss, physical damage to property and persons, loss of earnings, and an imputed value for the emotional damage to victims. Even excluding the emotional elements in cost and attributing, say, half of the remaining cost to mental illness, it still amounts to some $2 \%$ of national income, of which the taxpayer bears about half.

\section{Cost-effective psychological treatments}

To combat these costs, no country spends more than $1 \%$ of national income on mental health care (Figure 4). Most economically advanced countries spend less than $0.5 \%$ of national income on mental health care, and poorer countries spend far less. Thus, for example, the UK spends just $1 \%$ of national income to reduce the expense of conditions that cost the country some $7 \%$ of national income. On the face of it, that sounds inadequate. But whether it is enough depends on whether extra money for mental health care could be spent effectively. The evidence clearly shows that it can be.

The last 40 years have seen great progress in evidence-based psychological therapies (therapies whose effects have been studied by randomized methods and found to be (on average) substantial), especially cognitive behavioral therapy. For people with clinical depression or chronic anxiety disorders, such therapies lead to $50 \%$ recovery rates, with many other patients improving substantially. Such therapies also halve the likelihood of relapse, and in this respect they are more effective than drugs. A large majority of patients also prefer psychological therapy to drugs.

Yet in most countries, only a tiny fraction of people with depression or anxiety disorders receive evidence-based psychological therapy-a treatment supported by the Cochrane Collaboration (an independent, international organization dedicated to globally disseminating accurate information about the effects of health care) and by the UK's National Institute for Health and Care Excellence.

Figure 4. Mental health spending is very low in countries of every income level
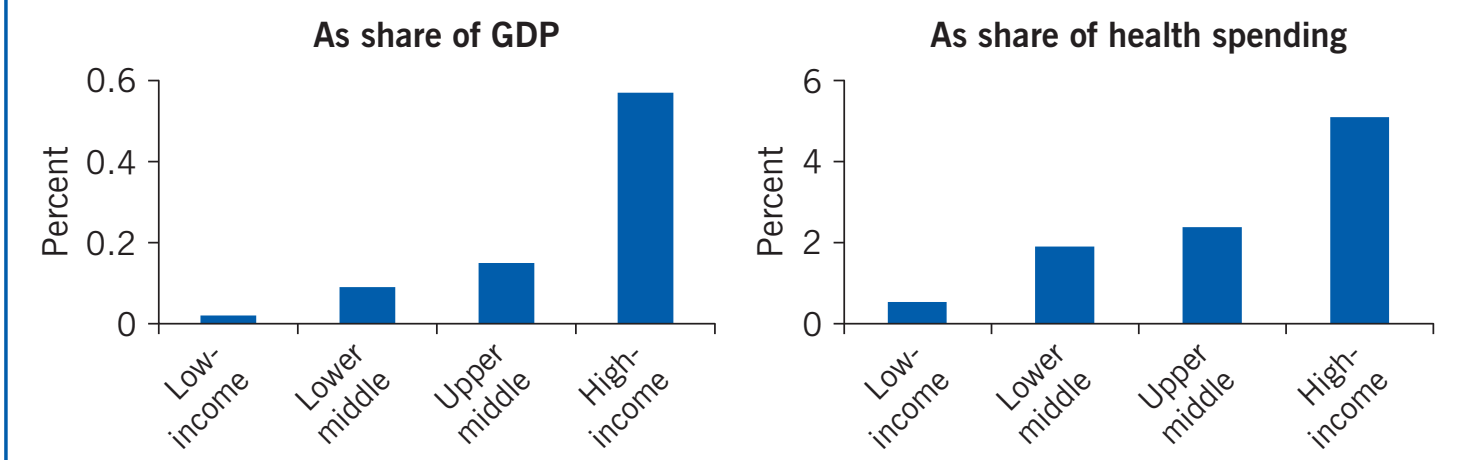

Source: Helliwell, J. F., R. Layard, and J. Sachs (eds). World Happiness Report 2013. New York: UN Sustainable Development Solutions Network, 2013. 
In 2007 , only $1 \%$ of people suffering from depression or anxiety disorders in the UK received such therapies. The situation has been transformed radically since then (see How the UK improved access to psychological therapies), based on an economic evaluation showing that providing these therapies involves no net cost to public funds [7]. Indeed, if savings on welfare benefits, lost taxes, and physical health care are included in the calculations, the treatments pay for themselves twice over. The saving exceeds the initial gross outlay.

\section{How the UK improved access to psychological therapies}

How might a government respond to the evidence on the effectiveness and economic benefits of psychological therapy? In the UK, the government decided in 2008 to launch a major national program to deliver evidence-based psychological therapies through the National Health Service called Improving Access to Psychological Therapies. The program includes a major training program for therapists. Trainees spend one or two days a week in college and the rest in supervised practice, with national curricula and national accreditation of trainees.

The aim of the program was to reach $15 \%$ of the population suffering from diagnosable depression or anxiety disorders (as measured in a population survey) by 2015. A range of evidence-based therapies would be offered, including cognitive behavioral therapy, interpersonal therapy, brief psychodynamic therapy, and counseling for depression. Patients could self-refer, and each patient's progress would be monitored at every session. Thus, the outcome is known for nearly all the patients treated: nearly half $(46 \%)$ recovered, and two-thirds showed significant improvement. In the next phase, recovery rates are expected to rise substantially following a series of improvements to the program.

This experience shows how a bad situation can be rapidly transformed. By 2020, the program is expected to expand from $15 \%$ of need (900,000 people) to $25 \%(1,500,000$ people). Many other countries have expressed an interest in setting up a similar program.

Source: Clark, D. M. "Implementing NICE guidelines for the psychological treatment of depression and anxiety disorders: The IAPT experience." International Review of Psychiatry 23:4 (2011): 318-327.

\section{Savings on welfare costs}

By preventing so many people from working, mental illness costs countries billions in welfare benefits and lost taxes. So treating these conditions successfully can lead to huge financial savings that fully repay the cost of the treatment.

The mechanism is simple. Making treatment available can help distressed people stay in work. And for people who are out of work, treatment can help them get back to work by giving them the psychological strength and confidence to face the labor market. Even a course of group cognitive behavioral therapy for unemployed people has been shown to double the numbers who find work.

British data can be used to put some numbers on the savings. Suppose 100 average people with depression and anxiety disorders (some working, some not) receive treatment. The available evidence indicates that over the next 25 months at least six of the 100 people who are treated will work who would not otherwise have done so. That means at least 150 extra months at work and off welfare benefits $(6 \times 25)$. Averaged over the 100 people 
treated, that amounts to at least 1.5 months off welfare benefits per person treated. From official figures on the cost of welfare benefits, the saving can be estimated at $£ 700$ for every month that someone is off welfare benefits, or an average of $£ 1,050$ per person treated $(1.5 \times 700)$. Taking the average of the cost of high- and low-intensity treatment yields a cost per person treated of $£ 950$. So the savings per person treated are at least as high as the cost of the treatment. There is hence no net cost to the taxpayer.

This argument was put to the British government some years ago and led to major changes in government policy (see How the UK improved access to psychological therapies). Similar arguments apply in any country.

How robust is a $6 \%$ assumption about the effects of therapy on employment? The most rigorous evidence comes from the US. A randomized controlled trial followed patients who had received cognitive behavioral therapy for depression over a two-year period. By the end of the period, $18 \%$ more were in work than would otherwise have been the case [8]. Patients allocated to anti-depressant medication for the same two-year period had no significant extra employment nor did patients allocated to receive a placebo pill. That is a very large difference.

Likewise, when a group of patients with general anxiety disorders or panic attacks received collaborative mental health care (designed to improve coordination between mental health and primary care), their employment rate 12 months later was up 16 percentage points over that of people who received "treatment as usual." And their absenteeism rate was down by the equivalent of one month (31 days) a year per person [9].

The only randomized controlled trial of employment effects in the UK covered some 300 long-term unemployed people. One group received seven weeks of group cognitive behavioral therapy, in weekly sessions lasting three hours each. The other group received an equal number of sessions of generalized social support. After four months, more than twice as many people in the cognitive behavioral therapy group than in the general support group had found full-time work-34\% compared with 13\% [10].

From the standpoint of citizens, it is not only the financial burden on the Treasury that matters. There is also the wider question of what the benefits are to society as a whole. This is the standard question in social cost-benefit analysis.

In this case, the costs are the same as they were to the Treasury-in the UK, roughly $£ 950$ per person in real resource costs. These costs need to be compared with the resulting real economic benefits. Savings on welfare benefit payments and increases in tax revenue are not a real benefit to the economy as a whole, since the state saves/gains money but the recipient loses it. The real economic benefit is the extra output produced by having more people at work. This benefit is measured as whatever is produced by an average of 1.5 months of extra work per person who received psychological therapy. The average monthly output of a British worker is more than $£ 4,000$. So, even taking half of that and then halving it again to allow for part-time work, still yields a real economic benefit of $£ 1,500$. This means that the output gains from the treatment exceed the cost of the treatment.

\section{Savings on physical health care}

All the gains discussed so far are attributable to the effect of psychological therapy on employment. But there is a second major economic benefit, which is related to physical 
health care: People who are depressed or anxious go to their primary care doctor more often and are referred more often to hospitals for physical problems. But when their mental health improves, they also use less physical health care.

Clearly the biggest effects on the use of physical health care will be found when psychological therapy is given to patients who also have a chronic physical illness. There is a huge overlap between mental illness and long-standing physical illness. In the UK, people with chronic physical illness account for $70 \%$ of health care costs. And the physical health care costs of people with a mental illness are $60 \%$ higher than the physical health care costs of other patients with the same physical condition at the same level of severity [5], [11].

In the US, there have been many studies of how physical health care costs change when people with physical illnesses also receive psychological treatment for their mental health conditions. A meta-analysis of 91 studies showed that psychological treatments reduced annual physical health care costs by an average of $20 \%$ [12]. In addition, in all but two of the 28 studies with data on the cost of psychological treatments, the physical health care savings exceeded the cost of the psychological treatment.

When these estimates are applied to English data, the annual cost of physical health care for people with a mental health illness is about $£ 6,000$ a year. Taking $20 \%$ of that amount yields $£ 1,200$ a year. Since about $60 \%$ of all mentally ill people in the UK are also physically ill, the average savings per person treated could be up to $£ 700$ a year. Within two years, the savings would be enough to repay the estimated $£ 950$ per person cost of psychological treatment.

In one well-documented case, the repayment was even faster. A general practice in the UK followed up 203 of its patients who suffered both mental and physical illness and who had been referred to a national program to deliver evidence-based psychological therapies through the National Health Service (NHS) (see How the UK improved access to psychological therapies). The study looked at how the practice's NHS costs had changed between the period before referral and two years later. Some of the patients had received no psychological treatment through the program, some had received partial treatment, and some had received full treatment. A comparison of matched samples of treated and untreated patients found that annual expenditure per person on physical health care fell by $£ 1,050$ with full psychological treatment and by $£ 500$ with partial treatment-savings big enough to pay for the treatment.

\section{LIMITATIONS AND GAPS}

Much of the evidence cited here is based on research in the UK and US, and many of the estimates are based on simplifying (but reasonable) assumptions.

Because of data limitations, estimates of the effect of mental illness on employment and welfare benefit costs likely understate the effects on welfare dependence. Most of the evidence on the economic benefits of treating mental illness is about the number of people with a mental illness who return to work rather than the number who no longer receive welfare benefits. 


\section{SUMMARY AND POLICY ADVICE}

Because mental illness is especially a disease of people of working age, it causes not only massive suffering but also great economic waste. People with a mental illness are less likely to be working and, if working, are more likely to be out sick or working below par. More than a third of the cases of disability and close to half of disability benefits are directly attributable to mental illness. If mentally ill people worked at the same rate as the rest of the population, total employment would be more than $4 \%$ higher, boosting production and tax revenues.

Mental health problems often exacerbate physical health problems, adding greatly to the cost of such physical health care. In the UK, the extra cost is $£ 10$ billion a year, and in the US, where health care costs take up a much larger share of a higher national income, the extra cost would be even higher. There is also the cost of crime attributable to mental illness, which one estimate puts at $2 \%$ of national income, with about half the cost borne by taxpayers.

Progress in evidence-based psychological therapies, especially cognitive behavioral therapy, has resulted in 50\% recovery rates for people with clinical depression or chronic anxiety disorders and substantial improvements for others. Therapy also halves the likelihood of a relapse. Even so, only a small fraction of people suffering from mental illness receive such treatment.

Psychological therapy is a remarkably good bargain. For each dollar or pound spent, roughly an equal amount is saved on welfare benefits and an equal amount on physical health care. Thus, with savings per person treated that are at least as high as the cost of treatment-likely higher-treating people suffering from a mental illness imposes no net cost on taxpayers. Putting that argument to the UK government in the mid-2000s led to major changes in government policy. Similar arguments apply in any country and should impress any government. Yet health care commissioners and insurers in the UK, the US, and elsewhere regularly see psychological therapy as an easy area to cut. They need to know that every time they do this, it costs rather than saves money.

\section{Acknowledgments}

The author thanks an anonymous referee and the IZA World of Labor editors for many helpful suggestions on earlier drafts. Previous work of the author contains a larger number of background references for the material presented here and has been used intensively in all major parts of this article [7] and Layard, R., and D. M. Clark. Thrive: The Power of Evidence-based Psychological Therapies. London: Penguin, 2014.

\section{Competing interests}

The IZA World of Labor project is committed to the IZA Guiding Principles of Research Integrity. The author declares to have observed these principles.

(c) Richard Layard 


\section{REFERENCES}

\section{Further reading}

Centre for Mental Health. The Economic and Social Costs of Mental Health Problems in 2009/10. London: Centre for Mental Health, 2010.

Layard, R., and D. M. Clark. Thrive: The Power of Evidence-based Psychological Therapies. London: Penguin, 2014.

\section{Key references}

[1] WHO. The Global Burden of Disease: 2004 Update. Geneva: WHO, 2008.

[2] Moussavi, S., S. Chatterji, E. Verdes, A. Tandon, V. Patel, and B. Ustun. "Depression, chronic diseases, and decrements in health: Results from the World Health Surveys." Lancet 370:9590 (2007): 851-858.

[3] OECD. Sick on the Job? Myths and Realities about Mental Health and Work. Paris: OECD Publishing, 2012.

[4] Goetzel, R. Z., S. R. Long, R. J. Ozminkowski, K. Hawkins, S. Wang, and W. Lynch. "Health, absence, disability, and presenteeism cost estimates of certain physical and mental health conditions affecting US employers." Journal of Occupational and Environmental Medicine 46:4 (2004): 398-412.

[5] Naylor, C., M. Parsonage, D. McDaid, M. Knapp, M. Fossey, and A. Galea. Long-term Conditions and Mental Health: The Cost of Co-morbidities. London: The King's Fund and Centre for Mental Health, 2012.

[6] Sainsbury Centre for Mental Health. The Chance of a Lifetime: Preventing Early Conduct Problems and Reducing Crime. London: Sainsbury Centre for Mental Health, 2009.

[7] Layard, R., D. M. Clark, M. Knapp, and G. Mayraz. "Cost-benefit analysis of psychological therapy." National Institute Economic Review 202:1 (2007): 90-98.

[8] Fournier, J. C., R. J. DeRubeis, J. Amsterdam, R. C. Shelton, and S. D. Hollon. "Gains in employment status following antidepressant medication or cognitive therapy for depression." British Journal of Psychiatry 206:4 (2015): 332-338.

[9] Rollman, B. L., B. H. Belnap, S. Mazumdar, P. R. Houck, F. Zhu, W. Gardner, and M. K. Shear. "A randomized trial to improve the quality of treatment for panic and generalized anxiety disorders in primary care." Archives of General Psychiatry 62:12 (2005): 1332-1341.

[10] Proudfoot, J., D. Guest, J. Carson, G. Dunn, and J. Gray. "Effect of cognitive-behavioural training on job-finding among long-term unemployed people." Lancet 350:9071 (1997): 96-100.

[11] NHS Confederation. Investing in Emotional and Psychological Wellbeing for Patients with Long-term Conditions. London: NHS Confederation Mental Health Network, 2012.

[12] Chiles, J. A., M. J. Lambert, and A. L. Hatch. "The impact of psychological interventions on medical cost offset: A meta-analytic review." Clinical Psychology: Science and Practice 6:2 (1999): 204-220.

\section{Online extras}

The full reference list for this article is available from:

http://wol.iza.org/articles/economics-of-mental-health

View the evidence map for this article:

http://wol.iza.org/articles/economics-of-mental-health/map 